\title{
Laparoscopic Colectomy for Colon Cancer After Liver Transplantation
}

\author{
Gustavo Rossi, MD, Ricardo Mentz, MD, Carlos A. Vaccaro, MD, PhD, Fernando A. Alvarez, MD, \\ Guillermo Ojea Quintana, MD
}

Section of Colon and Rectal Surgery, Department of General Surgery, Hospital Italiano de Buenos Aires, Juan D. Perón 4190, C1181ACH, Buenos Aires, Argentina (all authors).

\begin{abstract}
Introduction: Colon cancer in liver transplant patients is an uncommon clinical situation. These patients are considered of high risk and are classically treated with an open approach. Currently, there are very few reports in the literature regarding laparoscopic colectomy in the case of solid-organ transplant patients and none concerning a straight laparoscopic colectomy in a liver transplant patient.

Case Description: We present a 63-year-old female patient with a history of liver transplantation, who developed a left colon cancer 3 years after surgery. The tumor was located in the sigmoid colon, approximately $20 \mathrm{~cm}$ from the anal verge. The serum carcinoembryonic antigen was $4.5 \mathrm{ng} / \mathrm{mL}$ and a thoracoabdominal computed tomography scan ruled out metastatic disease. Surgery was scheduled and a laparoscopic left colectomy was successfully performed. The postoperative course was uneventful, and the patient was discharged on postoperative day 3 . After a 28-month follow-up, the patient remains free of disease.

Discussion: To the best of our knowledge, the present case represents the first reported straight laparoscopic colectomy in a liver transplant recipient. Laparoscopic colectomy for colon cancer in previous liver transplant patients is feasible and may be safely performed in the hands of experienced colorectal surgeons. Due to the known benefits of laparoscopic surgery, this alternative appears to be worthwhile and should be considered in selected liver transplant patients.
\end{abstract}

Key Words: Colon cancer, Laparoscopic colectomy, Laparoscopy, Liver transplantation

Citation Rossi G, Mentz R, Vaccaro CA, Alvarez FA, Quintana GO. Laparoscopic colectomy for colon cancer after liver transplantation. CRSLS e2014.00224. DOI 10.4293/CRSLS.2014.00224.

Copyright (C) 2014 SLS This is an open-access article distributed under the terms of the Creative Commons Attribution-Noncommercial-ShareAlike 3.0 Unported license, which permits unrestricted noncommercial use, distribution, and reproduction in any medium, provided the original author and source are credited.

Address correspondence to: Gustavo Rossi, MD, 4190 Juan D. Peron, C1181ACH, Buenos Aires, Argentina. Telephone: (54-11) 4959-0396 ext. 8480, Fax: (54-11) 4958-2200, E-mail: gustavo.rossi@hospitalitaliano.org.ar

\section{INTRODUCTION}

Laparoscopic colorectal surgery has shown several benefits over the open approach. ${ }^{1-4}$ However, this approach has been questioned in patients with previous abdominal surgery due to increased risk of intraoperative complications and higher conversion rate. ${ }^{5}$ There is very little evidence regarding laparoscopic colectomy in the case of solid-organ transplant patients. ${ }^{6}$ Although solid-organ transplant patients tend to be considered high risk, they will most likely benefit from minimally invasive surgery. Therefore, in this scenario, we hypothesized that a laparoscopic approach could be safe and feasible. We herein report a case of laparoscopic left colectomy for colon cancer in a liver transplant recipient.

\section{CASE REPORT}

We present a 63-year-old female patient with a history of liver transplantation for hepatitis $\mathrm{C}$ virus-induced cirrhosis 3 years before referral. She presented with a 2-month history of intermittent bleeding per rectum and weight loss. Except for a bilateral subcostal incision with an upper midline extension and a McBurney incision, nothing unusual was observed during the general examination (Figure 1). Her body mass index was 21 $\mathrm{kg} / \mathrm{m}^{2}$. Initial blood test confirmed anemia with a hemoglobin of $9.2 \mathrm{~g} / \mathrm{dL}$. Colonoscopy showed an ulcer- 


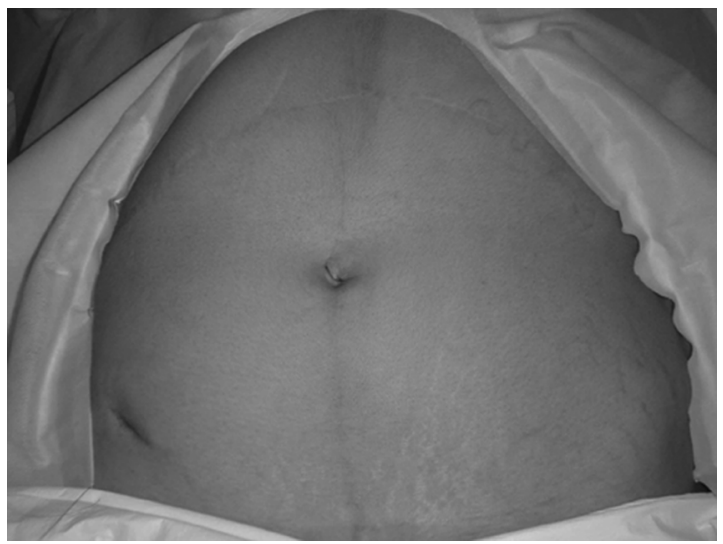

Figure 1. Patient's abdomen showing previous bilateral subcostal incision with upper midline extension and McBurney incision.

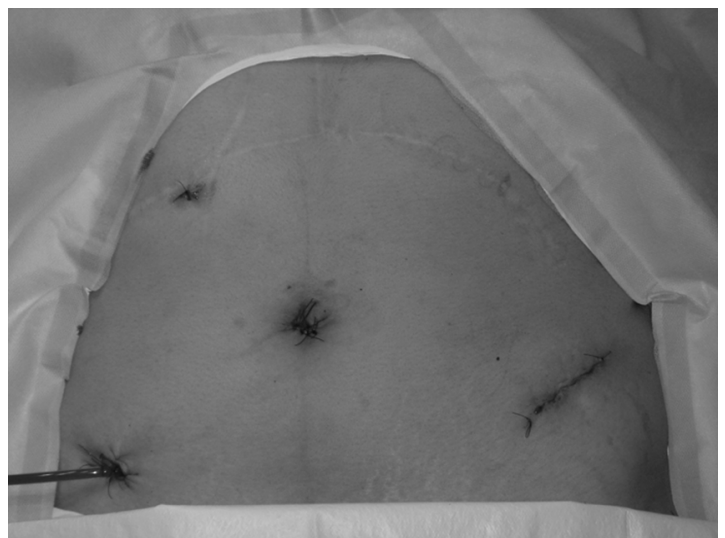

Figure 2. Trocar positioning and minilaparotomy at the left lower quadrant.

ated tumor of the sigmoid colon, approximately $20 \mathrm{~cm}$ from the anal verge. Biopsy of the lesion revealed a moderately differentiated adenocarcinoma. Serum carcinoembryonic antigen was $4.5 \mathrm{ng} / \mathrm{mL}$ (range $=0.5-$ 4). Liver function tests were normal. A computed tomography scan of the abdomen ruled out liver metastases and her chest $\mathrm{x}$-ray was normal.

Surgery was scheduled. The patient was placed in a modified lithotomy position using Allen stirrups under general anesthesia. Pneumoperitoneum was established through the open insertion of a $12-\mathrm{mm}$ umbilical port to a pressure between 12 and $14 \mathrm{~mm} \mathrm{Hg}$. Abdominal exploration with a $30^{\circ}$ laparoscope revealed multiple adhesions to the previous incision in the upper abdomen. The tumor was identified at the distal sig- moid colon. Three more trocars were sequentially placed under direct laparoscopic view. First, a 5-mm trocar was placed in the left lower quadrant for cold adhesiolysis using endoscopic scissors. Once extensive adhesions were taken down, a $12-\mathrm{mm}$ trocar and a $5-\mathrm{mm}$ trocar were placed in the right lower quadrant and right upper quadrant, respectively (Figure 2). Dissection began with the mobilization of the mesocolon from the right side (medial-to-lateral approach) identifying the left ureter. Subsequently, the intracorporeal division of the inferior mesenteric artery and vein was performed with a Ligasure V (Valleylab, Boulder, Colorado). The sigmoid and descending colon were mobilized laterally including the splenic flexure. The proximal rectum was divided at the rectosigmoid junction with a linear cutting stapler. The specimen was delivered through the left lower quadrant by enlarging the previous port incision using an Alexis wound protector (Applied Medical, Rancho Santa Margarita, California). After the specimen was resected and an anvil placed within the proximal colon, the pneumoperitoneum was re-established and a circular-stapled colorectal anastomosis was performed. Finally, a hydro-pneumatic test was carried out to rule out the presence of an anastomotic leak. Blood loss was $100 \mathrm{~mL}$ and the operative time was 210 minutes.

The patient had an uneventful recovery and was discharged on the third postoperative day after advancing to a full diet. Immunosuppression with cyclosporine was temporarily discontinued until oral intake was reestablished 48 hours after surgery. Thirty days postoperatively, no complications were reported. Histologic examination of the specimen (Figure 3) revealed a stage II disease with 13 negative lymph nodes (pT3,

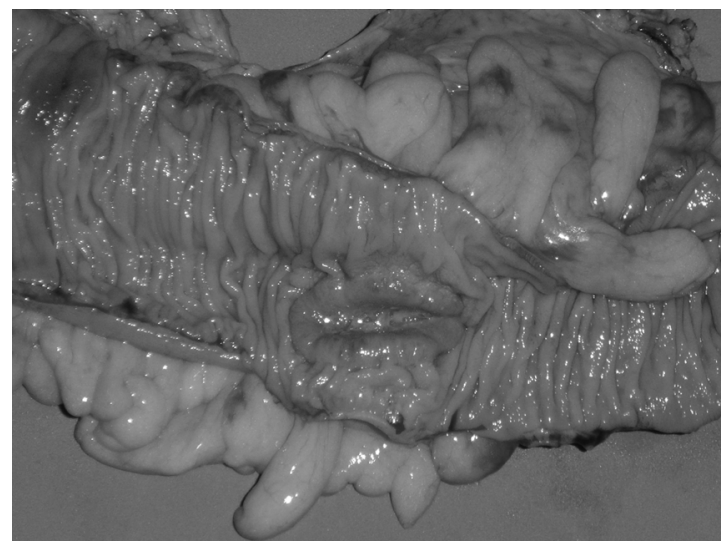

Figure 3. Surgical specimen of left hemicolectomy showing the ulcerated tumor on the sigmoid colon. 
pN0, M0). After a 28-month follow-up, the patient remains free of disease.

\section{DISCUSSION}

Laparoscopic colorectal surgery has become routine in treating colorectal diseases at high-volume surgical centers with experience in advanced laparoscopic surgical techniques. The COST (Clinical Outcomes of Surgical Therapy) trial 7 and other recent studies ${ }^{8,9}$ have shown that the oncological effectiveness of laparoscopic colon resections is comparable to that of the open technique. In addition, laparoscopic surgery has been used in more complex cases such as colorectal resections in patients with previous abdominal surgery, ${ }^{10}$ obesity, ${ }^{11,12}$ and, more rarely, with solid-organ transplants. ${ }^{6}$

Until recently, it was thought that the complexity of a laparoscopic procedure might increase in patients with a medical history of previous abdominal surgery. However, some investigators state that prior surgery does not adversely affect postoperative outcomes and should not be considered a contraindication for laparoscopic colorectal surgery. ${ }^{10,13}$ This is especially important in patients with intra-abdominal solid-organ transplants because they are high-risk patients and laparoscopic colorectal surgery is associated with lower morbidity and mortality. ${ }^{1,14}$

To date, there are only 2 reports of colorectal resections in patients with intra-abdominal solid-organ transplants using minimally invasive surgery and none regarding straight laparoscopic colectomy in liver transplant patients. Rivas et $\mathrm{al}^{6}$ described laparoscopic-assisted colectomies for colon cancer in 3 kidney transplant recipients. These investigators mentioned that colon resections in these cases were simplified due to the contralateral location of the allografts. Furthermore, they observed that laparoscopic surgery avoided perioperative immunosuppression. Hochman and Pemberton $^{15}$ reported a successful hand-assisted laparoscopic total proctocolectomy and ileal pouch-anal anastomosis for chronic ulcerative colitis after a liver transplant. According to the investigators, hand-assisted laparoscopic surgery can reduce operative time while maintaining the benefits of conventional laparoscopy, and a previous transplant should not be considered a contraindication for laparoscopic approach.

Although adhesiolysis may have increased the operative time, it did not prevent adequate resection of the left colon following strict oncological criteria. Additionally, transplant patients who have very large previous incisions, benefit greatly from laparoscopic surgery due to the minimal damage to the abdominal wall. Therefore, laparoscopy may be a good alternative for the treatment of colon cancer in patients with a previous liver transplant.

\section{CONCLUSIONS}

To the best of our knowledge, the present case represents the first reported straight laparoscopic colectomy in a liver transplant recipient. Laparoscopic colectomy for colon cancer in previous liver transplant patients is feasible and may be safely performed in the hands of experienced colorectal surgeons. Due to the known benefits of laparoscopic surgery, this alternative appears to be worthwhile and should be considered in selected liver transplant patients.

\section{References:}

1. Braga M, Vignali A, Gianotti L, et al. Laparoscopic versus open colorectal surgery: a randomized trial on short-term outcome. Ann Surg. 2002;236(6):759-766.

2. Chen $\mathrm{HH}$, Wexner $\mathrm{SD}$, Iroatulam $\mathrm{AJ}$, et al. Laparoscopic colectomy compares favorably with colectomy by laparotomy for reduction of postoperative ileus. Dis Colon Rectum. 2000; 43(1):61-65.

3. Weeks JC, Nelson H, Gelber S, et al., for the COST Study Group. Short-term quality-of-life outcomes following laparoscopic-assisted colectomy vs open colectomy for colon cancer: a randomized trial. JAMA. 2002;287(3):321-328.

4. Schwenk W, Haase O, Neudecker J, Müller JM. Short term benefits for laparoscopic colorectal resection. Cochrane Database Syst Rev. 2005;(3):CD003145.

5. Franko J, O'Connell BG, Mehall JR, et al. The influence of prior abdominal operations on conversion and complication rates in laparoscopic colorectal surgery. JSLS. 2006;10(2):169-175.

6. Rivas H, Martinez JL, Delgado S, Lacy AM. Laparoscopic assisted colectomies in kidney transplant recipients with colon cancer. J Laparoendosc Adv Surg Tech A. 2004;14(4):201-204.

7. Clinical Outcomes of Surgical Therapy Study Group. A comparison of laparoscopically assisted and open colectomy for colon cancer. N Engl J Med. 2004;350(20):2050-2059.

8. Fleshman J, Sargent DJ, Green E, et al., for the COST Study Group. Laparoscopic colectomy for cancer is not inferior to open surgery based on 5-year data from the COST Study Group trial. Ann Surg. 2007;246(4):655-662. 
9. Leung KL, Kwok SP, Lam SC, et al. Laparoscopic resection of rectosigmoid carcinoma: prospective randomised trial. Lancet. 2004;363(9416):1187-1192.

10. Law WL, Lee YM, Chu KW. Previous abdominal operations do not affect the outcomes of laparoscopic colorectal surgery. Surg Endosc. 2005;19:326-330.

11. Delaney CP, Pokala N, Senagore AJ, et al. Is laparoscopic colectomy applicable to patients with body mass index $>30$ ? A case-matched comparative study with open colectomy. Dis Colon Rectum. 2005;48(5):975-981.

12. Makino T, Shukla PJ, Rubino F, Milsom JW. The impact of obesity on perioperative outcomes after laparoscopic colorectal resection. Ann Surg. 2012;255(2):228-236.
13. Arteaga González I, Martín Malagón A, López-Tomassetti Fernández EM, Arranz Durán J, Díaz Luis H, Carrillo Pallares A. Impact of previous abdominal surgery on colorectal laparoscopy results: a comparative clinical study. Surg Laparosc Endosc Percutan Tech. 2006;16(1):8-11.

14. Noel JK, Fahrbach K, Estok R, et al. Minimally invasive colorectal resection outcomes: short-term comparison with open procedures. J Am Coll Surg. 2007;204(2):291-307.

15. Hochman DJ, Pemberton JH. Hand-assisted laparoscopic total proctocolectomy and ileal pouch-anal anastomosis after liver transplant for primary sclerosing cholangitis. Surg Laparosc Endosc Percutan Tech. 2007;17(1):56-57. 